This is a self-archiving document (manuscript version):

Microscopic origin of the aluminium assisted spiking effects in $n$ type silicon solar cells

By: Heinz, Friedemann D.; Breitwieser, Matthias; Gundel, Paul; König, Markus; Hörteis, Matthias; Warta, Wilhelm; Schubert, Martin C.

Published in: Solar Energy Materials and Solar Cells

Volume 131, December 2014, Pages 105-109 (Please be aware: Page numbering in this manuscript can be different to published version!)

Publisher: Elsevier | Year: 2014

DOI: 10.1016/j.solmat.2014.05.036

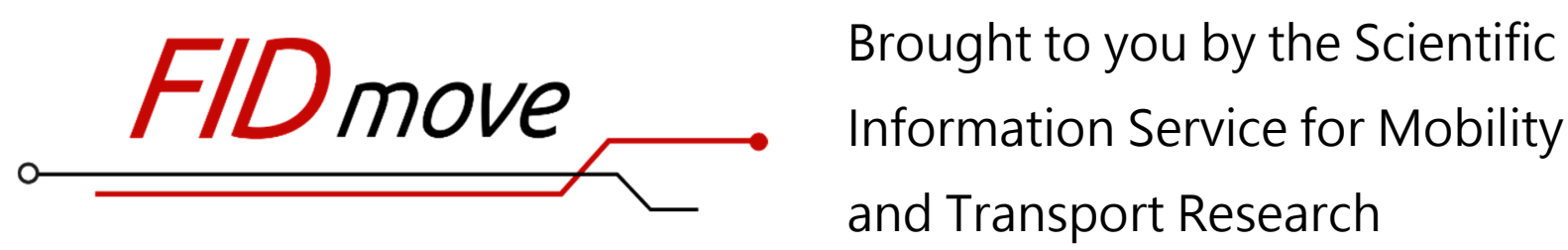

Fachinformationsdienst Mobilitäts- und Verkehrsforschung

Website: www.fid-move.de

Repository: publish.fid-move.de

Contact: publish@fid-move.de

(C) 2020. This manuscript version is made available under the CC-BYNC-ND 4.0 license.

http://creativecommons.org/licenses/by-nc-nd/4.0/ 


\title{
Microscopic origin of the aluminium assisted spiking effects in n-type silicon solar cells
}

\author{
Friedemann D. Heinz ${ }^{\mathrm{a}, *}$, Matthias Breitwieser ${ }^{\mathrm{a}}$, Paul Gundel ${ }^{\mathrm{b}}$, Markus König ${ }^{\mathrm{b}}$, \\ Matthias Hörteis ${ }^{b}$, Wilhelm Warta ${ }^{a}$, Martin C. Schubert ${ }^{a}$ \\ ${ }^{a}$ Fraunhofer Institute for Solar Energy Systems, Heidenhofstr. 2, 79110 Freiburg, Germany \\ ${ }^{\mathrm{b}}$ Heraeus Precious Metals GmbH \& Co. KG, Heraeusstraße 12-14, 63450 Hanau, Germany \\ * Corresponding author. Tel.: +49 761/4588 5321, fax: +49 761/4588 \\ 9250. E-mail address: friedemann.heinz@fraunhofer.ise.de (F.D. Heinz).
}

\begin{abstract}
A B S T R A C T
Contact formation with silver (Ag) thick film pastes on boron emitters of n-type crystalline silicon ( $\mathrm{Si}$ ) solar cells is a nontrivial technological task. Low contact resistances are up to present only achieved with the addition of aluminium (Al) to the paste. During contact formation, Al assisted spiking from the paste into the silicon emitter and bulk occurs, thus leading to a low contact resistance but also to a deterioration of other cell parameters. Both effects are coupled and can be adjusted by choosing proper $\mathrm{Al}$ contents of the paste and temperatures for contact formation. In this work the microscopic electric properties of single spikes are presented. These microscopic results, i.e. alterations of the local emitter doping density, the pronounced local recombination activity at the interface between spikes and $\mathrm{Si}$ and its influence on the charge collection efficiency, are used to explain the observed dependencies of global cell parameters on the $\mathrm{Al}$ content of contact pastes.
\end{abstract}

\section{Introduction}

Up to now, $\mathrm{Al}$ is a necessity in industrial $\mathrm{Ag}$ thick film pastes for good contact formation on boron emitters, i.e. a low contact resistivity. The use of $\mathrm{Al}-\mathrm{Ag}$ pastes for the emitter metallisation introduces a mechanism which is both, beneficial and harmful: "spiking" of an $\mathrm{Al}-\mathrm{Ag}$ phase from the paste into the silicon material. Above about $660{ }^{\circ} \mathrm{C}, \mathrm{Al}$ particles in the paste melt and the $\mathrm{Ag}$ matrix facilitates $\mathrm{Al}$ transport to the $\mathrm{Si}$ interface and an $\mathrm{Al}-\mathrm{Ag}-\mathrm{Si}$ contact is formed [1,2]. In contrast to the commonly used name "Al spike" for these v-shaped contacts we will use the name "Ag-Al spikes", as the spikes consist of mainly Ag (see below). $\mathrm{Ag}-\mathrm{Al}$ spikes are responsible for good contact formation. If spiking occurs through the emitter, this mechanism can lead to a Schottky-type direct contact between the metal and the silicon bulk material. The inevitable negative influence of $\mathrm{Ag}-\mathrm{Al}$ spikes on global cell parameters like open circuit voltage $\left(V_{\text {oc }}\right)$ and grid resistance has been investigated [3-5] and is confirmed within this work; the $V_{\text {oc }}$ measured after metallisation with a standard $\mathrm{Al}$ containing Ag thick film paste was measured to be about $25 \mathrm{mV}$ lower than the implied $V_{\text {oc }}\left(\mathrm{i} V_{\text {oc }}\right.$ ) of $660 \mathrm{mV}$ measured before metallisation. Furthermore, by doubling the fraction of metallised 
area, the drop in $V_{\text {oc }}$ increased correspondingly after firing. However, the underlying local electrical properties of the spikes and their specific impact on cell performance remained unclear up to now.

To investigate the contact formation and deterioration caused by $\mathrm{Al}$ assisted spiking we choose a two-step approach: (1) observation of the influence of $\mathrm{Al}$ content in the paste on the global cell performance; (2) microscopic analyses of the local electrical properties in the vicinity of single spikes, of which the number and size scale with $\mathrm{Al}$ content in the paste.

\section{Influence of Al content of paste}

To specify the influence of the composition of the paste used for $\mathrm{p}^{+}$metallisation, samples with different pastes were processed: a standard reference paste, pastes with different amounts of $\mathrm{Al}$ compared to the reference (without $\mathrm{Al}$ and with $0.5 \times, 2 \times$, $4 \times$, and $6 \times$ the amount of Al compared to the standard paste), a non-contacting paste (i.e. a paste which is not fired through the passivation) and a sample without metallisation. The $6 \times$ higher amount of Al led to a drop of cell efficiency from $18.6 \%$ to $17.2 \%$. Both, $\mathrm{i} V_{\mathrm{oc}}$ and pseudo fill factor ( $\mathrm{pFF}$ ) decrease with rising $\mathrm{Al}$ content of the paste (for pFF see Fig. 1, the dependence of $V_{\mathrm{oc}}$ is similar). In accordance to [4], a higher $V_{\text {oc }}$ was observed using a non-contacting paste. The plot in Fig. 2 reveals a reduction of 


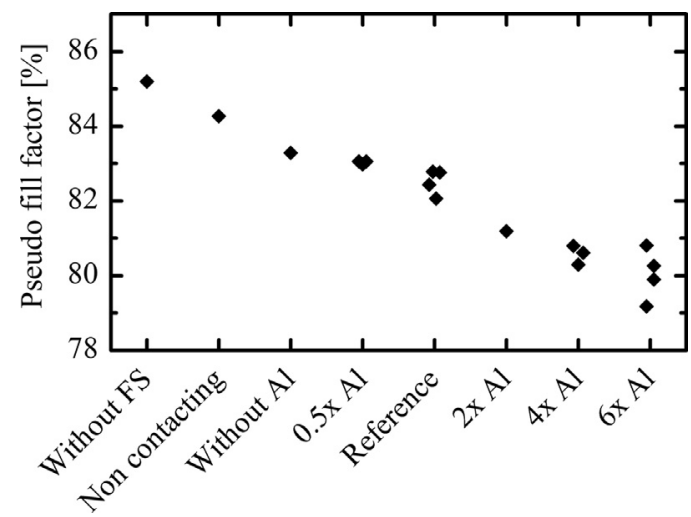

Fig. 1. Decrease of the global pseudo fill factor with increasing $\mathrm{Al}$ content of the $\mathrm{Ag}-\mathrm{Al}$ metallisation paste.

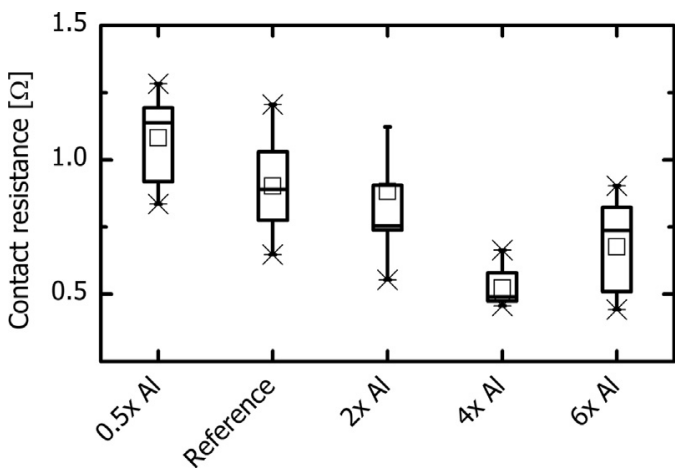

Fig. 2. Decrease of contact resistance with higher Al content in the paste.

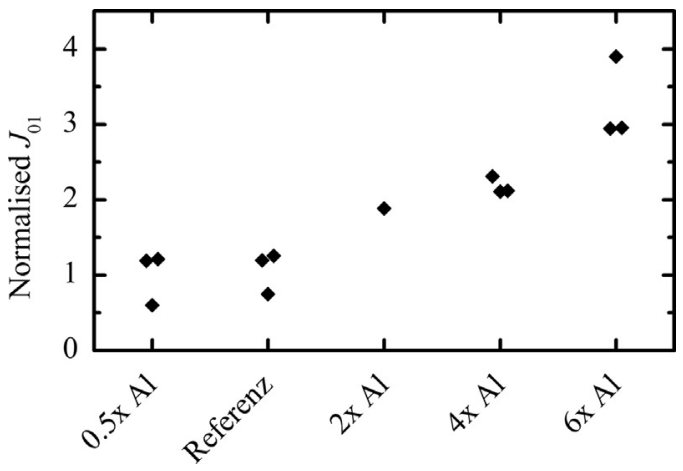

Fig. 3. Increase of $J_{01}$ with $\mathrm{Al}$ content in the paste.

contact resistance with $\mathrm{Al}$ content in the paste. The slight increase of contact resistance with $6 \times$ higher Al content is caused by an increased line resistance, which limits the measured resistance in this case. Additionally to the decrease of pFF and $V_{\text {oc }}$ we also observe an increase of $J_{01}$, which indicates a surface recombination issue in the emitter.

The observed effects can be explained postulating an Al assisted spiking mechanism [2]. The experimental microscopic proof of both the beneficial and harmful properties of $\mathrm{Ag}-\mathrm{Al}$ spikes explaining the global effects is given in the following section.

\section{Microscopic characterisation of $\mathrm{Ag}-\mathrm{Al}$ spikes}

In order to trace the observed effects of $\mathrm{Ag}-\mathrm{Al}$ spikes on global parameters back to their microscopic origin, cross sections cut 
from the samples are investigated in the following. The cross sections were diamond and SiC polished. The high resolution electric and spectroscopic techniques are based on a confocal microscope, which focusses a laser to a spot with diffraction limited size. Techniques with sub-micron resolution are employed by detecting:

- the scattered light: Micro-Raman Spectroscopy ( $\mu$ RS) enables to map the emitter doping density at low [6] and carrier lifetime at high laser excitation [7];

- the photoluminescence (PL) of generated electron-hole pairs: from Micro-PL Spectroscopy ( $\mu$ PLS) [8], the carrier lifetime can be extracted;

- the photo-generated current: Micro-Light Beam Induced Current $(\mu \mathrm{LBIC})[9]$.

A $355 \mathrm{~nm}$ laser is used in combination with a $40 \times$ lens with $\mathrm{NA}=0.60$, PL and Raman scattered light are excited with $532 \mathrm{~nm}$ laser light and detected with a $50 \times$ lens with $N A=0.65$ and $100 \times$ lens with $N A=0.9$, respectively. In the case of $\mu$ PLS Auger recombination caused by the used high injection strongly reduces the diffusion length of generated carriers to below $1 \mu \mathrm{m}$. This confinement of carriers into a small volume is enhanced by strong dilution of carriers away from the excitation spot due to their 3D diffusion and thus leads to sub-micron resolution for all methods Fig. 3.

\subsection{Description of samples for microscopic investigations}

A commercial $\mathrm{Ag}-\mathrm{Al}$ paste is screen-printed on a random pyramid textured n-type $\mathrm{CZ}$ wafer with a diffused $90 \Omega$ /sq Boron emitter, $70 \Omega /$ sq Phosphorus back surface field and fired at a set peak temperature of about $905{ }^{\circ} \mathrm{C}$. With this temperature slightly above usual firing temperatures a further deterioration of the resulting cell is observed. In parallel, we observe an increased number and size of $\mathrm{Ag}-\mathrm{Al}$ spikes on polished cross sections of these samples, presumed to be responsible for the deterioration [2]. The more pronounced influence of these enlarged spikes simplifies their microscopic characterisation.

\subsection{Microscopic pre-characterisation}

Fig. 4a shows a representative SE contrast image of the cross section cut of a sample. The sketch in Fig. 4c illustrates the observations: the pattern in the top part is the metallisation paste; the area in the lower part is the silicon bulk. The light band in between (dotted in grey in the sketch) is the $\mathrm{p}^{+}$emitter; SE contrast can be used to distinguish between areas of different types of doping [10].

Spikes are identified by their typical $\mathrm{V}$ shape, homogeneous filling with an $\mathrm{Ag}-\mathrm{Al}$ alloy and overlap with the emitter; in the model of Al assisted spiking $\mathrm{Si}$ (i.e. also the emitter) is consumed during spike formation and replaced by an $\mathrm{Ag}-\mathrm{Al}$ alloy. EDX confirmed the features of the $\mathrm{Al}$ assisted spiking mechanism (Fig. 4c): the Al content in the spikes is about $1 \%$, which is according to [2] where $\mathrm{Al}$ is needed to create spikes via an $\mathrm{Ag}-\mathrm{Al}-\mathrm{Si}$ alloy phase, but where the spikes themselves consist mainly of Ag. The spikes are depicted in the sketch by the area dashed in red. Both spikes are classified as "deep", i.e. punching through the emitter, in contrast to "shallow" spikes, which are fully located within the emitter.

\subsection{Micro-spectroscopic characterisation}

The doping density measured with $\mu \mathrm{RS}$ at these spikes (Fig. 4d) supports the finding of SE contrast, that the spikes interrupt the 

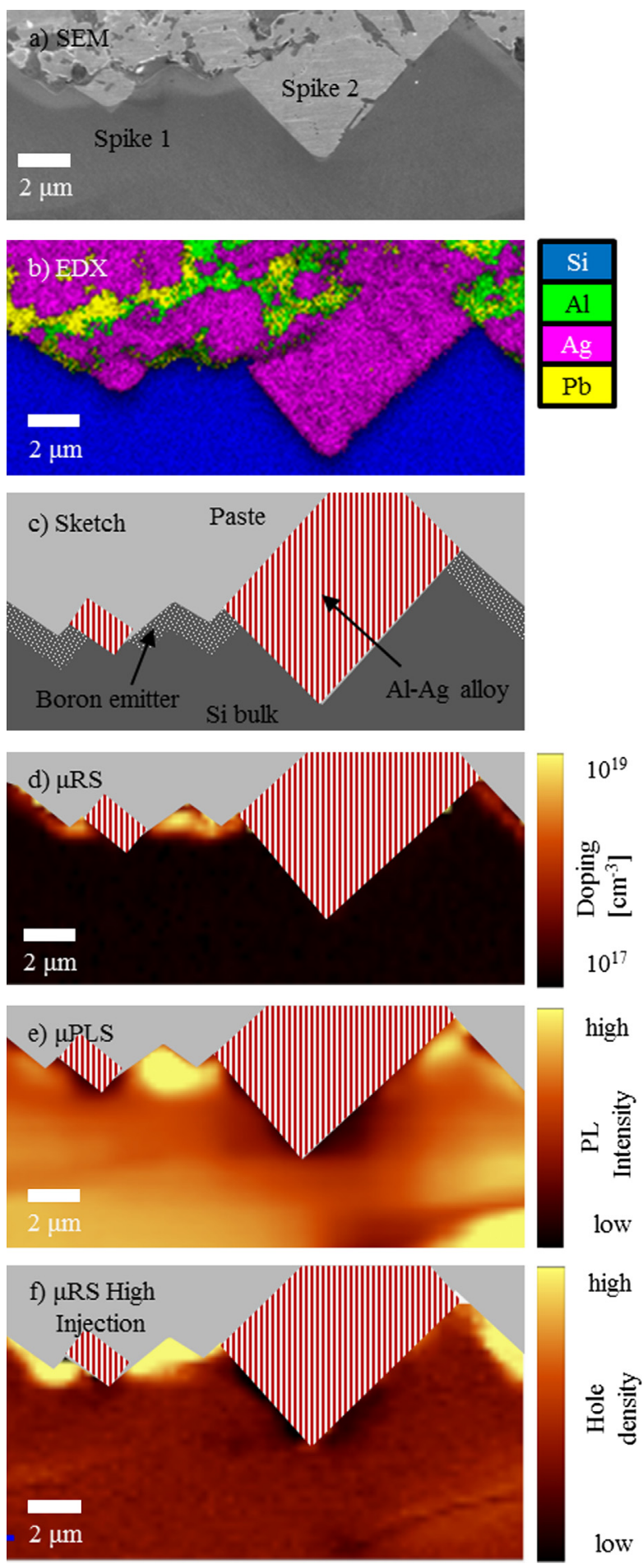

Fig. 4. Microscopic measurements at spikes labelled 1 and 2. In (b) the chemical analysis performed with EDX is shown. The sketch shown in (c) explains the SEM image (a). The spikes which punched through the emitter (d) are highly recombination active $(\mathrm{e} / \mathrm{f})$. (For interpretation of the references to colour in this figure, the reader is referred to the web version of this article.)

emitter. In addition to the information on emitter depth obtained from SE contrast lateral inhomogeneities within the emitter, caused by inhomogeneous depths of the Boron diffusion due to the surface structure, are visible. Within the spatial resolution limit, no highly doped region is visible beneath the spikes in these samples with both SE contrast and $\mu$ RS. 
Fig. 4e and f shows the PL intensity and hole density measured with $\mu$ PLS [8] and high injection $\mu$ RS [7], respectively. The bright areas are due to the high emitter doping density (compare Fig. 4d) [11]. The dark line in the lower right is a surface scratch. The observation of interest is the strong signal decrease at the spikes. Comparison with the SE contrast image shows that deep spikes only occur where there is a high recombination activity. We thus associate sites of high recombination activity to deep spikes. The hole density measured with $\mu \mathrm{RS}$ (f), which is less influenced by carrier diffusion and exhibits a higher spatial resolution compared to the $\mu \mathrm{PLS}$ image (e), is reduced only directly at the $\mathrm{Ag}-\mathrm{Al}$ spikes.

We attribute these low lifetimes to a high surface recombination velocity at the $\mathrm{Al}-\mathrm{Ag}-\mathrm{Si}$ interfaces, which is confirmed by the carrier diffusion-limited $\mu$ PLS measurement, showing a drop in PL which extends deep into the Si bulk. The high recombination at the $\mathrm{Al}-\mathrm{Ag}-\mathrm{Si}$ interface suggests that a metal-silicon contact is formed at the spikes as proposed in [2], with both $\mathrm{Al}$ and $\mathrm{Ag}$ (both having barrier heights of $>0.7 \mathrm{eV}$ on n-type $\mathrm{Si}[12,13]$ ) supporting the formation of an ohmic contact within the $\mathrm{p}^{+}$emitter and a Schottky contact within the n-type bulk Si. It is also possible that a highly doped $\mathrm{Al}$ emitter is formed beneath deep spikes inside the n-type bulk. A microscopic proof for a highly doped Al layer could not be attained with SE contrast, $\mu \mathrm{EDX}$ or $\mu \mathrm{RS}$, meaning that if an $\mathrm{Al}$ emitter is established it has well below $100 \mathrm{~nm}$ emitter depth. In both cases, a rectifying junction is established.

\subsection{Micro-electric investigation}

For a more detailed characterisation of the charge collection of the established rectifying junction besides and in the vicinity of these spikes $\mu$ LBIC measurements are conducted. Therefore, a large area is scanned with SE contrast to categorise the spikes as exemplarily shown in Fig. 5a. Deep spikes are marked with red arrows with diamonds, shallow spikes with green arrows with a circle. In Fig. 5b the superposition of the whole area SE contrast image and the photocurrent locally excited with a $532 \mathrm{~nm}$ laser recorded using $\mu \mathrm{LBIC}$ is shown. The mapping of the photocurrent, which is given by the collection efficiency of the junction and recombination losses, with $532 \mathrm{~nm}$ laser excitation shows two areas where the width and intensity of the photocurrent is quenched. These areas appear to be correlated to deep spikes. The photo-current density (integrated over the depth of the junction) below all spikes is depicted in Fig. 6. The extreme values always occur, if a shallow and a deep spike are close. Still, the collected photo-current beneath spikes varies significantly between shallow Ag-Al spikes.

In the area where the sign "paste" is written, there is low photocurrent, but no deep Ag-Al spikes. This could be explained by the absence of shallow $\mathrm{Ag}-\mathrm{Al}$ spikes and thus a high contact resistance in this area leading to a low charge collection.

To evaluate the origin of this quenching a photocurrent map was recorded using $355 \mathrm{~nm}$ laser excitation (Fig. 5c). The junction width shows no more inhomogeneities. Due to the low penetration depth the $355 \mathrm{~nm}$ laser of $<10 \mathrm{~nm}$, carriers are generated near the surface. Thus the effective carrier lifetime is, in contrast to $532 \mathrm{~nm}$ excitation, limited by the unpassivated cross section surface. Other localised recombination active sites consequently have less influence on the effective lifetime which itself limits charge collection. This observation indicates that the deteriorating effect on the charge collection observed with $532 \mathrm{~nm}$ laser excitation is in fact due to the spikes' high recombination activity.

The uniformity of the junction recorded with UV laser excitation in Fig. 5c furthermore confirms that a rectifying junction, i.e. a Schottky barrier, is established at the direct interface between $\mathrm{Ag}-\mathrm{Al}$ and n-type base $\mathrm{Si}$. No evidence for the formation of an $\mathrm{Al}$ emitter could be found (with neither SE contrast, $\mu$ PLS, $\mu$ RS, EDX or 


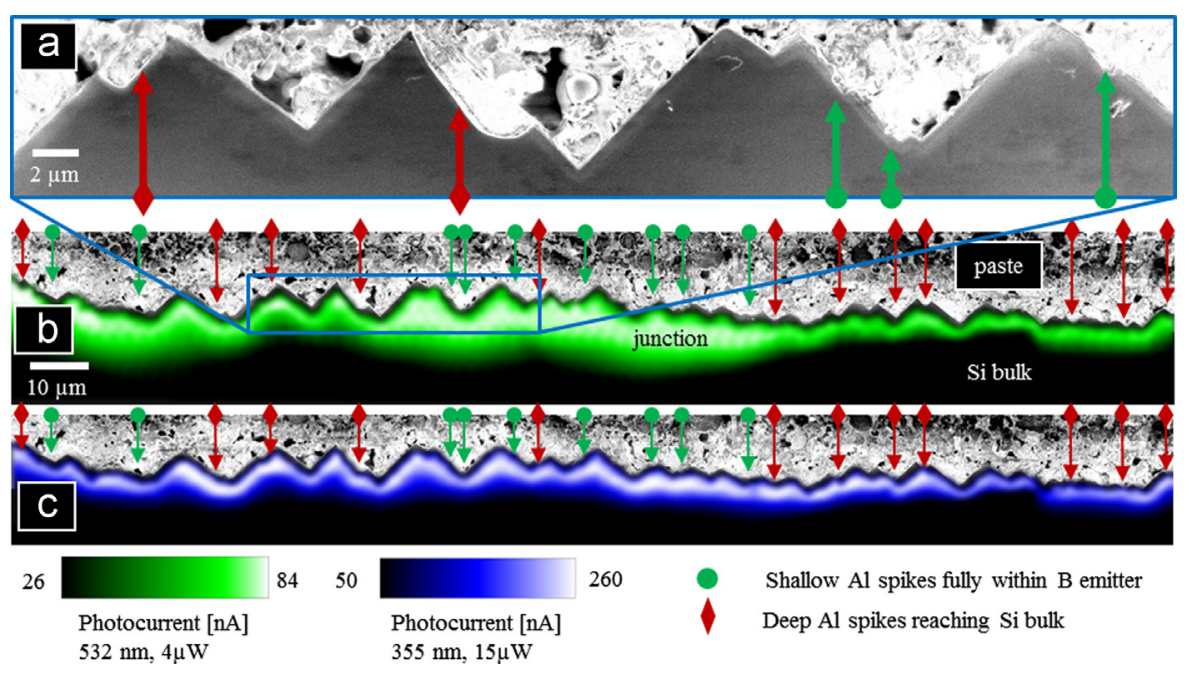

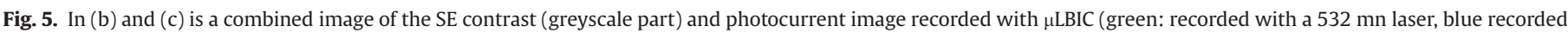

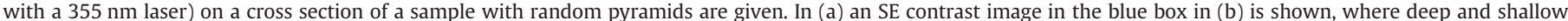

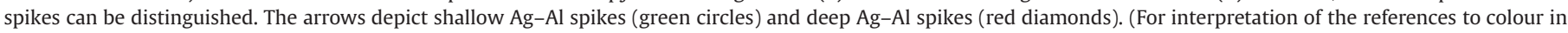
this figure legend, the reader is referred to the web version of this article.)

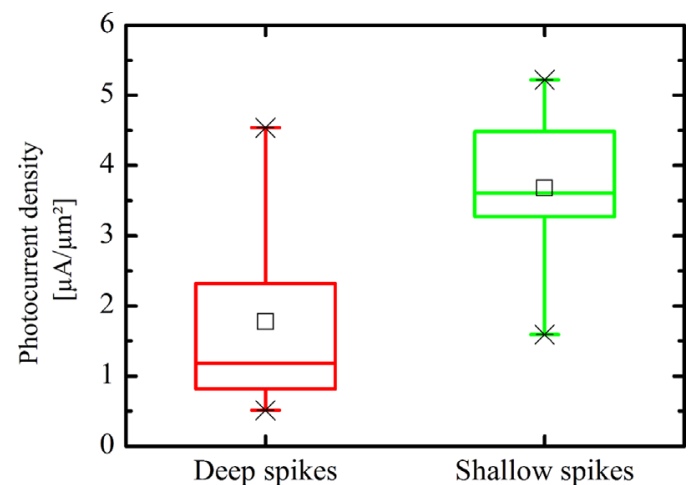

Fig. 6. Photocurrent density beneath deep and shallow spikes, averaged over a $5 \mu \mathrm{m}$ wide area.

TEM). The risk of shunting of deep spikes persists in case a nonideal Schottky diode is formed.

\section{Discussion of microscopic origin of global effects}

The size and number of spikes and accordingly the Al-Ag-Si interface area were observed to increase with $\mathrm{Al}$ content. A decrease in contact resistance with $\mathrm{Al}$ content in the paste as observed in Fig. 2 can consequently be explained by an increase in size and number of spikes.

$\mu$ LBIC measurements show that the junction quality is influenced by spike sizes: high recombination velocities at the Ag-Al$\mathrm{Si}$ interfaces limit the charge collection efficiency. The high recombination activities also present at the $\mathrm{Ag}-\mathrm{Al}-\mathrm{Si}$ interfaces, which were also directly observed by micro-spectroscopic means, explain the drop in $V_{\mathrm{oc}}$ and $\mathrm{pFF}$ with increasing $\mathrm{Al}$ content in the paste. Also, considering that the high recombination activity of all spikes is mainly within the emitter, the origin of the increase of $J_{01}$ becomes clear.

This high recombination activity is pronounced at deep spikes as they are not field effect passivated by the B emitter. However, $\mu$ LBIC measurements showed that Schottky contacts are established at deep spikes. Their possibly non-ideal diode character may influence the globally observed decrease in pFF, and involve the risk of shunting. 


\section{Conclusions}

The electrical properties of $\mathrm{Ag}-\mathrm{Al}$ spikes have been determined by microscopic optical spectroscopy. The combined results from SEM, EDX, $\mu \mathrm{RS}, \mu \mathrm{PLS}$ and $\mu \mathrm{LBIC}$ enabled to trace the globally observed deterioration in cell parameters like pFF, $V_{\text {oc }}$ and $J_{01}$ and contact resistance reduction attributed to the $\mathrm{Al}$ in Si thick film pastes down to the microscopic electrical properties of $\mathrm{Ag}-\mathrm{Al}$ spikes: a high recombination activity at the $\mathrm{Al}-\mathrm{Ag}-\mathrm{Si}$ interfaces of the spikes, the formation of a Schottky contact at deep spikes and thus an increased probability of local shunting as well as high charge collection efficiency in the vicinity of shallow spikes. Our results suggest that parameters like Al content and firing temperature have to be carefully adjusted to generate small $\mathrm{Ag}-\mathrm{Al}$ spikes of sufficient number to ensure low contact resistivity without pronounced recombination losses at large $\mathrm{Al}-\mathrm{Ag}-\mathrm{Si}$ interfaces.

\section{Acknowledgements}

The author would like to thank Michaela Winterhalder and Gernot Emanuel for sample preparation.

\section{References}

1 R. Lago, L. Pérez, H. Kerp, I. Freire, I. Hoces, N. Azkona, F. Recart, J.C. Jimeno, Screen printing metallization of boron emitters, Prog. Photovolt.: Res. Appl. 18 (1) (2010) 20

2 Markus König, Alexander Rudl, Nicole Georg, Matthias Hörteis, Advanced Model for the Contact Formation of Al-Containing Ag Thick Film Paste on Boron-Doped Emitter of Si Solar Cells, nPV Workshop, 2013.

3 A. Edler, V.D. Mihailetchi, C. Comparotto, L.J. Koduvelikulathu, R. Kopecek, R. Harney, T. Böscke, J. Lossen On the metallization losses of bifacial n-type silicon solar cells. in: Proceedings of the 27th EU-PVSEC, 1429, 2012.

4 I.G. Romijn, B.B. Van Aken, J. Anker, A.R. Burgers, A. Gutjahr, B. Heurtault, M. Koppes, E. Kossen, M. Lamers, D.S. Saynova, C.J.J. Tool, F. Lang, G. Li, H. Wang, Z Hu, P.R. Venema, A.H.G. Vlooswijk, Industrial implementation of efficiency improvements in n-type solar cells and modules. in: Proceedings of 27th EUPVSEC, 533, 2012.

5 Tim Böske, Progress on n-Type Cells With Boron Emitters. nPV Workshop, 2012.

6 F.D. Heinz, W. Warta, M.C. Schubert, Optimizing micro raman and PL spectroscopy for solar cell technological assessment, Energy Proc. 27 (2012) 208.

7 Paul Gundel, Martin C. Schubert, Friedemann D. Heinz, Jan Benick, Ivo Zizak, Wilhelm Warta, Submicron resolution carrier lifetime analysis in silicon with fano resonances, Phys Status Solidi (RRL) - Rapid Res. Lett. 4 (7) (2010) 160.

8 Paul Gundel, Friedemann D. Heinz, Martin C. Schubert, Johannes A. Giesecke, Wilhelm Warta, Quantitative carrier lifetime measurement with micron resolution, J. Appl. Phys. 108 (3) (2010) 033705.

9 M. Breitwieser, F.D. Heinz, A. Büchler, J. Schön, M. Kasemann, W. Warta, M. C. Schubert, Analysis of solar cell cross sections with mirco-light beam induced current ( $\mu$ LBIC), SolMat (2014) (SiliconPV2014 special issue).

10 T.H.P. Chang, W.C. Nixon, Electron beam induced potential contrast on unbiased planar transistors, Solid-State Electron. 10 (7) (1967) 701.

11 F.D. Heinz, P. Gundel, W. Warta, M.C. Schubert, Doping density in silicon and solar cells analyzed with micrometer resolution, IEEE J. Photovolt. 3 (1) (2013) 341.

12 H.C. Card, Aluminum-silicon Schottky barriers and ohmic contacts in integrated circuits, IEEE Trans. Electron Devices 23 (6) (1976) 538.

13 D.K. Schroder, D.L. Meier, Solar cell contact resistance - a review, IEEE Trans. Electron Devices 31 (5) (1984) 637. 